\title{
The application of two-dimensional fluorescence correlation spectroscopy on the interaction between bovine serum albumin and prulifloxacin
}

\author{
Mao-Yun Xue a,b Ai-Ping Yang a,b ${ }^{\text {a, }}$, Mei-Hua Ma ${ }^{\text {a,b }}$ and Xiao-Hua Li ${ }^{\text {a,b,* }}$ \\ ${ }^{a}$ Department of Engineering Technology, Jiangsu Institute of Economic and Trade Technology, \\ Nanjing, P. R. China \\ ${ }^{\mathrm{b}}$ Research and Development Centre of Food Safety Engineering Technique of Jiangsu, Nanjing, \\ P. R. China
}

\begin{abstract}
The interaction between bovine serum albumin (BSA) and prulifloxacin was investigated by ultraviolet spectrophotometer (UV) and fluorescence spectroscopy in this paper. Two-dimensional (2D) correlation spectroscopy was applied to the analysis of fluorescence spectra. The results of spectroscopic measurements suggested that prulifloxacin (PL) have a strong ability to quench the intrinsic fluorescence of bovine serum albumin through static quenching procedure. Thermodynamic parameter enthalpy changes $(\Delta H)$ and entropy changes $(\Delta S)$ were calculated. Owing to the spectral resolution enhancement in $2 \mathrm{D}$ correlation spectroscopy, the structure change of prulifloxacin can be observed.
\end{abstract}

Keywords: Prulifloxacin, bovine serum albumin, fluorescence quenching, two-dimensional fluorescence correlation spectroscopy

\section{Introduction}

Prulifloxacin (Fig. 1), the prodrug of ulifloxacin (AF3013, NM394), is a broad-spectrum oral fluoroquinolone antibacterial agent [11].

Serum albumins are one of the most abundant proteins in blood plasma. Many drugs are transported in the blood upon binding to albumin. The binding ability of drug-albumin in blood stream may have a significant impact on distribution, free concentration and metabolism of drug [3,5]. Thus, it is important and necessary to study the interaction of drug with serum albumins at molecular level $[1,8,21,24]$.

Spectroscopic method has been widely applied in investigating drug binding with albumin under physiological conditions because of its accuracy, sensitivity, rapidity and convenience of usage $[10,19]$. It can reveal the accessibility of drugs to albumin's fluorophores, help understand the binding mechanisms of albumin-drug and provide information of the structural features that determine the therapeutic effectiveness of drug.

\footnotetext{
${ }^{*}$ Corresponding author: Xiao-Hua Li, Department of Engineering Technology, Jiangsu Institute of Economic and Trade Technology and Research and Development Centre of Food Safety Engineering Technique of Jiangsu, Nanjing 210007, Jiangsu Province, P. R. China. Tel.: +86 25 86569303; E-mail: xiaohuali57@163.com.
} 
<smiles>Cc1oc(=O)oc1CN1CCN(c2cc3c(cc2F)c(=O)c(C(=O)O)c2n3C(C)S2)CC1</smiles>

Fig. 1. The structure of prulifloxacin.

In this study, we investigated the interaction between prulifloxacin and bovine serum albumin by fluorescence spectroscopy, and revealed that hydrophobic interaction plays an important role in the binding between prulifloxacin and BSA. Furthermore, we analyzed fluorescence spectra by 2D [4,6,13-17] correlation fluorescence spectroscopy to reveal the details of binding interaction between prulifloxacin and BSA. The perturbation mode employed in the 2D correlation analysis is fluorescence quenching. Using the 2D spectroscopy, it is also possible to probe the specific order of chemical functional changes upon perturbation, perform detailed dynamics study of molecule vibration.

\section{Experimental}

\subsection{Materials}

Prulifloxacin was purchased from National Institute for Identification of Pharmaceutical and Biological Products. The purity of prulifloxacin was no less than 99.9\%. BSA, being electrophoresis grade reagents, was obtained from Sigma. The buffer Tris had a purity of no less than $99.5 \%$ and $\mathrm{NaCl}, \mathrm{HCl}$, etc. were all of analytical purity. The samples were dissolved in Tris- $\mathrm{HCl}$ buffer solution $(0.05 \mathrm{~mol} / \mathrm{l}$ Tris, $0.15 \mathrm{~mol} / \mathrm{l} \mathrm{NaCl}, \mathrm{pH}$ 7.4). The solutions of albumin were prepared $15 \mathrm{~min}$ before experiment. All solutions were used with doubly distilled water.

\subsection{Equipments and spectral measurements}

The UV spectra were recorded at room temperature on a TU-1901 spectrophotometer (Puxi Analytic Instrument Ltd. of Beijing, China) equipped with $1.0 \mathrm{~cm}$ quartz cells. All fluorescence spectra were recorded on Perkin Elmer LS-50B Spectrofluorimeter (PE, CT, USA) equipped with $1.0 \mathrm{~cm}$ quartz cells and thermostat bath, the excitation wavelength was $280 \mathrm{~nm}$, the excitation and the emission slit widths were set at $3 \mathrm{~nm}$, appropriate blanks corresponding to the buffer were subtracted to correct background fluorescence.

\subsection{Principles of fluorescence quenching}

Fluorescence quenching is described by the well-known Stern-Volmer equation [2]:

$$
F_{0} / F=1+K_{\mathrm{Sv}}[Q]
$$


where $F_{0}$ and $F$ denote the steady-state fluorescence intensities in the absence and in the presence of quencher, respectively, $K_{\mathrm{SV}}$ is the Stern-Volmer quenching constant, and $[Q]$ is the concentration of the quencher. Hence, Eq. (1) was applied to determine $K_{\mathrm{SV}}$ by linear regression of a plot of $F_{0} / F$ against $[Q]$.

\section{Results and discussion}

\subsection{Fluorescence quenching}

BSA molecule has two tryptophan residues that possess intrinsic fluorescence: Trp-134 in the first subdomain IB of the albumin molecule and Trp-212 in subdomain IIA. Trp-212 is located within a hydrophobic binding pocket of the protein and Trp-134 is located on the surface of the albumin molecule $[12,18]$. A valuable feature of intrinsic fluorescence of proteins is the high sensitivity of tryptophan to its local environment [22]. Changes in emission spectra of tryptophan are common in response to protein conformational transitions, subunit association, substrate binding, or denaturation [23]. So, the intrinsic fluorescence of proteins can provide considerable information about their structure and dynamics, and is often considered on the study of protein folding and association reactions. BSA solutions excited at $280 \mathrm{~nm}$ emit fluorescence attributable mainly to tryptophan residues. The effect of prulifloxacin on tryptophan residues fluorescence intensity was shown in Fig. 2. As the data showed, the fluorescence intensity of BSA decreased regularly with the increasing concentration of prulifloxacin, which indicated that prulifloxacin could bind to BSA. In order to discuss the results within the linear concentration range, we selected carrying out the experiment within the linear part of Stern-Volmer dependence $\left(F_{0} / F\right.$ against $[Q])$. Figure 3 displayed the Stern-Volmer plots of the quenching of BSA tryptophan residues fluorescence by prulifloxacin at different temperatures.

The plot showed that within the investigated concentrations, the results agreed with the Stern-Volmer (Eq. (1)). The Stern-Volmer plot does not show deviation towards the $y$-axis obviously at the experimental concentration range which is an indication that either dynamic quenching or static quenching is predominant. In Table 1, the binding constants obtained for the Stern-Volmer method are listed for prulifloxacin with BSA. The results showed that the Stern-Volmer dynamic quenching constant $K_{\mathrm{SV}}$

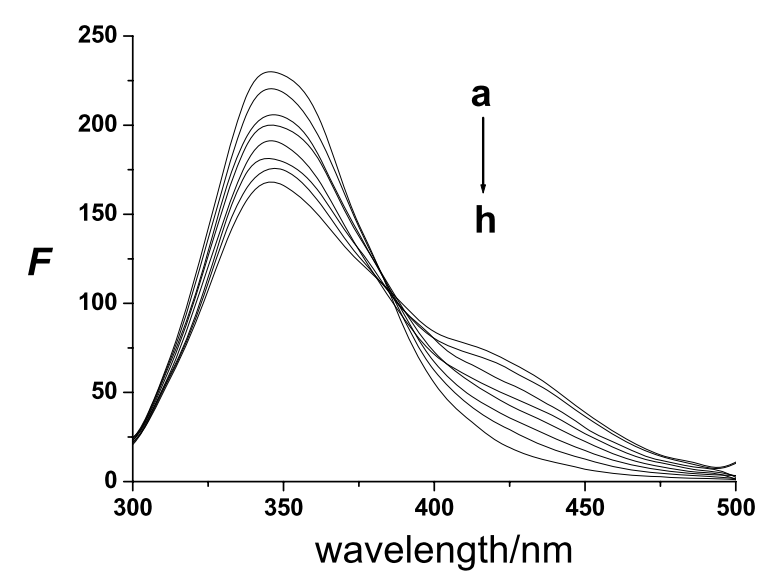

Fig. 2. The fluorescence emission spectra of BSA at various concentration of prulifloxacin. The $C_{\mathrm{BSA}}$ was $5.0 \times 10^{-7} \mathrm{~mol} / \mathrm{l}$, while the $C_{\mathrm{PL}}$ corresponding to $0,2.0,4.0,6.0,8.0,10.0,12.0,14.0 \times 10^{-7} \mathrm{~mol} / \mathrm{l}$ from a to $\mathrm{h}$. 


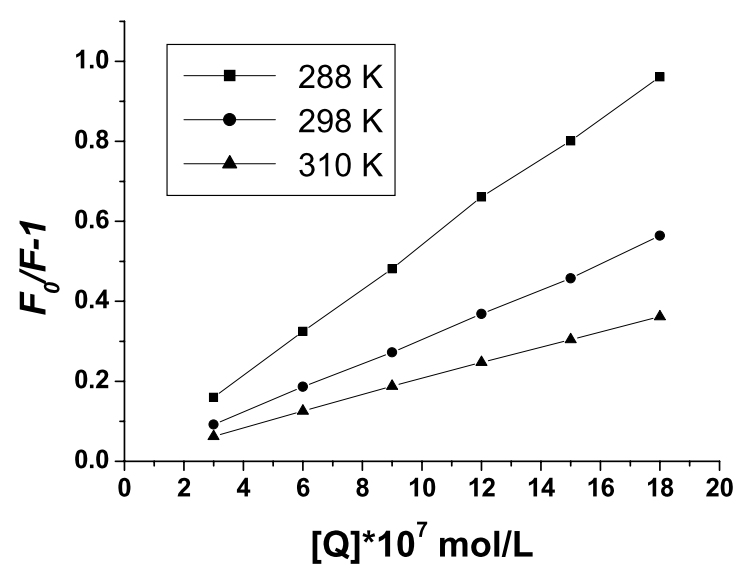

Fig. 3. The Stern-Volmer plots for the quenching of BSA by prulifloxacin at different temperatures. $C_{(\mathrm{BSA})}=5.0 \times$ $10^{-7} \mathrm{~mol} / \mathrm{l} ; \mathrm{pH} 7.40 ; \lambda_{\mathrm{ex}}=280 \mathrm{~nm}$.

Table 1

Binding and quenching constants according to Stern-Volmer curves

\begin{tabular}{ccccc}
\hline $\mathrm{pH}$ & Temperature $(\mathrm{K})$ & $K_{\mathrm{sv}}\left(10^{4} \mathrm{l} / \mathrm{mol}\right)$ & $K_{q}\left(10^{12} \mathrm{l} / \mathrm{mol} / \mathrm{s}\right)$ & $R$ \\
\hline 7.4 & 288.15 & $6.29 \times 10^{5}$ & 17 & 0.9993 \\
& 298.15 & $1.05 \times 10^{5}$ & 5.74 & 0.9992 \\
& 310.15 & $6.68 \times 10^{4}$ & 2.98 & 0.9990 \\
\hline
\end{tabular}

was inversely correlated with temperatures, which indicated that, the probable quenching mechanism of fluorescence of BSA by prulifloxacin is not initiated by dynamic collision but compound formation [22]. In other words, the fluorescence quenching of BSA results from complex formation is predominant, while from dynamic collision could be negligible. In Table 1, the binding constants obtained for the Stern-Volmer method are listed for prulifloxacin with BSA.

\subsection{Binding site and binding constant}

For static quenching, the relationship between fluorescence quenching intensity and the concentration of quenchers can be described by the binding constant formula [9]:

$$
\log \left[\left(F_{0}-F\right) / F\right]=\log K_{\mathrm{a}}+n \log [Q]
$$

where $K_{\mathrm{a}}$ is the binding constant, and $n$ is the number of binding sites. After the fluorescence quenching intensities on BSA at $347 \mathrm{~nm}$ were measured, the double-logarithm algorithm was assessed by Eq. (2).

In Table 2, the binding constants $K_{\mathrm{a}}$ and binding sites $n$ are listed for prulifloxacin associated with BSA. The results showed that the binding constants $K_{\mathrm{a}}$ were decreased with the rising temperature, which may indicate forming an unstable compound [7]. The unstable compound would be partly decomposed when the temperature rising. The values of $n$ approximately equal to 1 indicated the existence of just a single binding site in BSA for prulifloxacin. 
Table 2

Binding constant $K_{\mathrm{a}}$ and binding sites $n$ for prulifloxacinBSA at different temperatures

\begin{tabular}{lcc}
\hline Temperature $(\mathrm{K})$ & $K_{\mathrm{a}}(\mathrm{l} / \mathrm{mol})$ & $n$ \\
\hline 288.15 & $6.29 \times 10^{5}$ & 1.03 \\
298.15 & $1.05 \times 10^{5}$ & 1.01 \\
310.15 & $6.68 \times 10^{4}$ & 0.98 \\
\hline
\end{tabular}

\subsection{Thermodynamic parameters and nature of the binding forces}

The acting forces between a drug and a biomolecule may include hydrogen bond, van der Waals force, electrostatic force and hydrogen bond interaction force and so on [20]. Because the temperature effect is very small, the interaction enthalpy change can be regarded as a constant if the temperature range is not too wide. Therefore, from the following equations:

$$
\begin{aligned}
& \Delta G=-R T \ln K_{\mathrm{a}}, \\
& \ln \left(K_{2} / K_{1}\right)=\Delta H\left(1 / T_{1}-1 / T_{2}\right) / R, \\
& \Delta G=\Delta H-T \Delta S,
\end{aligned}
$$

where $\Delta H, \Delta G$ and $\Delta S$ are, respectively, enthalpy change, free energy change and entropy change, $\Delta H$ and $\Delta S$ for the binding interaction between prulifloxacin and BSA are calculated to be 41,957 and $226,448 \mathrm{~kJ} / \mathrm{mol}$. Because of enthalpy change $\Delta H<0$ and entropy change $\Delta S>0$, it can be deduced that the acting force for the binding reaction between BSP and HSA is mainly a hydrophobic interaction [20].

\section{2D correlation analysis of the fluorescence of BSA and prulifloxacin}

We employed a quenching perturbation technique to carry out the $2 \mathrm{D}$ correlation analysis. Figure 2 represents fluorescence spectra of BSA and prulifloxacin, which obtained by changing the amount of the prulifloxacin. As can be seen from Fig. 2, BSA has strong fluorescence emission with a peak at $347 \mathrm{~nm}$ on excitation at $280 \mathrm{~nm}$, upon the addition of prulifloxacin; the fluorescence intensity was continuously decreased in both proteins. Using these spectra, we carried out the 2D analysis. The synchronous and asynchronous correlation maps are shown in Fig. 4.

The synchronous 2D spectrum of the sample shows a strong auto peak at 347 and $420 \mathrm{~nm}$. In the synchronous plot, diagonal peaks are referred to as auto peaks. The intensity of auto peaks is always positive, and they always represent the overall extent of the concentration-induced fluctuation of spectral intensity. Hence, the strong auto peak at 347 and $420 \mathrm{~nm}$ indicate the significant concentration-induced intensity variation of the spectral features at these positions vary greatly. The peak in $350 \mathrm{~nm}$ (Fig. 4(a)) is due to the fact that both Trp bands reduce their intensities with increasing prulifloxacin. It might be referred to a change in the conformation of tryptophan micro-region caused by the interaction of BSA with prulifloxacin. The peak in $420 \mathrm{~nm}$ is due to the structure changed of prulifloxacin. Through our previous work, prulifloxacin is probably bound to Trp-212 residue mainly through the hydrophobic interaction, Trp-212 residue plays an important structural role in the formation of the IIA binding site by limiting the solvent accessibility and besides that it participates in additional hydrophobic packing 


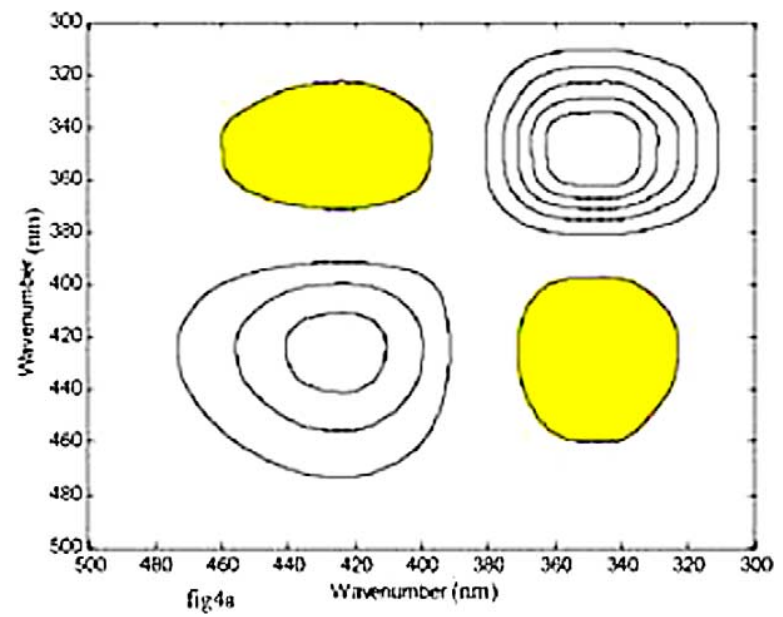

(a)

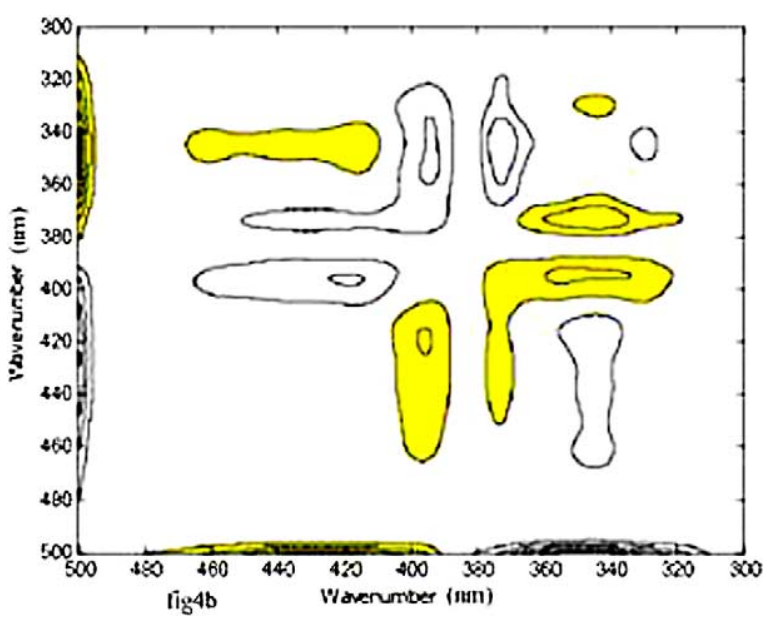

(b)

Fig. 4. 2D fluorescence correlation spectra of BSA and prulifloxacin. (a) Synchronous 2D fluorescence correlation map and (b) asynchronous 2D fluorescence correlation map.

interaction, after prulifloxacin segments insert into the hydrophobic region of BSA, prulifloxacin which structure changed formed multimer and generated tenuous fluorescence.

An asynchronous plot has only off-diagonal peaks; the presence of asynchronous peaks indicates that the intensity responses of corresponding bands occur at different rates. A positive asynchronous peak at (v1, v2) means that the intensity at $\mathrm{v} 1$ changes faster compared to that at $\mathrm{v} 2$, while the negative asynchronous peak implies the opposite phenomenon. This feature is very useful in differentiating overlapped bands due to different spectral origin. There is a cross-peak at 347 and $420 \mathrm{~nm}$ in Fig. 4(b), we realize that $\Phi(347,420)<0$ and $\Psi(347,420)<0$, where the symbols $\Phi$ and $\Psi$ denote synchronous and asynchronous peaks, respectively. According to Noda [15], this fact indicates that the structure change of prulifloxacin before the fluorescence of BSA changed its intensity. Prulifloxacin was hydrophilicity, and so it was difficult to bind with the Trp-212. But with the increasing of concentration of prulifloxacin, the structure changed and formed lipid soluble multimer, which then insert into the hydrophobic pocket of BSA. This procedure might be referred to a change in the conformation of tryptophan micro-region caused by the interaction of BSA with prulifloxacin. The conformation of BSA was changed, and the polarity around the tryptophan residues was increased and the hydrophobicity was decreased, therefore, resulted in the interaction between BSA and prulifloxacin.

\section{Conclusion}

In this paper, we investigated the nature and magnitude of the interaction of prulifloxacin with BSA by spectroscopic method. The protein fluorescence quenching mechanism was mainly static quenching process and the structure changed of prulifloxacin played an important role during the binding process. Two-dimensional correlation spectroscopy was applied to the analysis of fluorescence spectra. In the 2D correlation maps, weak bands could be clearly detected by 2D correlation method. From the combination of synchronous and asynchronous correlation maps, we could extract information that the structure of prulifloxacin was changed before the fluorescence of BSA changed its intensity. 


\section{References}

[1] S. Ashoka, J. Seetharamappa, P.B. Kandagal and S.M.T. Shaikh, Investigation of the interaction between trazodone hydrochloride and bovine serum albumin, J. Lumine 121 (2006), 179-186.

[2] C.Y. Chen, K. Chen, Q. Long, M.H. Ma and F. Ding, Structural characterization and DNA-binding properties of Sm(III) complex with ofloxacin using spectroscopic methods, Spectroscopy 23 (2009), 103-111.

[3] C.Y. Chen, M.H. Ma, J.Q. Zhang, L.C. Wang and B.R. Xiang, Spectroscopic investigation of the interaction of bovine serum albumin with a novel cardiac agent V-09, Spectroscopy 22 (2008), 43-50.

[4] C.Y. Chen, B.R. Xiang, L.Y. Yu, T. Wang and B. Zhao, The application of two-dimensional fluorescence correlation spectroscopy on the interaction between bovine serum albumin and paeonolum in the presence of Fe(III), Spectrosc. Lett. 41 (2008), 385-392.

[5] C.Y. Chen, J.H. Zhou and X.T. Gu, Binding studies of paeonolum with bovine serum albumin using spectroscopic methods, Spectroscopy 21 (2007), 53-60.

[6] H. Fukuma, K. Nakashima, Y. Ozaki and I. Noda, Two-dimensional fluorescence correlation spectroscopy IV: Resolution of fluorescence of tryptophan residues in alcohol dehydrogenase and lysozyme, Spectrochim. Acta A 65 (2006), 517-522.

[7] Y.J. Hu, Y. Liu, X.S. Shen, X.Y. Fang and S.S. Qu, Studies on the interaction between 1-hexylcarbamoyl-5-fluorouracil and bovine serum albumin, J. Mol. Struct. 738 (2005), 143-147.

[8] Y.J. Hu, Y. Liu, T.Q. Sun, A.M. Bai, H.Q. Lu and Z.B. Pi, Binding of anti-inflammatory drug cromolyn sodium to bovine serum albumin, Int. J. Biol. Macromol. 39 (2006), 280-285.

[9] C.Z. Huang, K.A. Li and S.Y. Tong, Determination of nucleic acids by a resonance light-scattering technique with $\alpha, \beta, \gamma, \delta$-tetrakis [4-(trimethylammoniumyl)phenyl] porphine, Anal. Chem. 68 (1996), 2259-2263.

[10] B.P. Kamat and J. Seetharamappa, Mechanism of interaction of vincristine sulphate and rifampicin with bovine serum albumin: A spectroscopic study, J. Chem. Sci. 117 (2005), 649-655.

[11] S.J. Keam and C.M. Perry, Prulifloxacin, Drugs 64 (2004), 2221-2234.

[12] U. Kragh-Hansen, Molecular aspects of ligand binding to serum albumin, Pharmacol. Rev. 33 (1981), 17-53.

[13] K. Nakashima, S. Yasuda, Y. Ozaki and I. Noda, Two-dimensional fluorescence correlation spectroscopy. I. Analysis of polynuclear aromatic hydrocarbons in cyclohexane solutions, J. Phys. Chem. A. 104 (2000), 9113-9120.

[14] K. Nakashima, K. Yuda, Y. Ozaki and I. Noda, Two-dimensional fluorescence correlation spectroscopy: Resolution of fluorescence of tryptophan residues in horse heart myoglobin, Appl. Spectrosc. 57 (2003), 1381-1385.

[15] I. Noda, Two-dimensional infrared spectroscopy, J. Am. Chem. Soc. 111 (1989), 8116-8118.

[16] I. Noda, Progress in two-dimensional (2D) correlation spectroscopy, J. Mol. Struct. 799 (2006), 2-15.

[17] I. Noda, Recent advancement in the field of two-dimensional correlation spectroscopy, J. Mol. Struct. 883, 884 (2008), 2-26.

[18] T. Peter, Serum albumin, Adv. Protein Chem. 37 (1985), 161-245.

[19] H.M. Rawel, S.K. Frey, K. Meidtner, J. Kroll and F.J. Schweigert, Determining the binding affinities of phenolic compounds to proteins by quenching of the intrinsic tryptophan fluorescence, Mol. Nutr. Food Res. 50 (2006), 705-713.

[20] P.D. Ross and S. Subramanian, Thermodynamics of protein association reaction: forces contribution to stability, Biochemistry 20 (1981), 3096-3102.

[21] S.M.T. Shaikh, J. Seetharamappa, P.B. Kandagal and S. Ashoka, Binding of the bioactive component isothipendyl hydrochloride with bovine serum albumin, J. Mol. Struct. 786 (2006), 46-52.

[22] A. Sharma and S.G. Schulman, Introduction to Fluorescence Spectroscopy, Wiley, New York, 1999.

[23] A. Sulkowska, Interaction of drugs with bovine and human serum albumin, J. Mol. Struct. 614 (2002), 227-232.

[24] T. Wang, B.R. Xiang, Y. Wang, C.Y. Chen, Y. Dong, H.S. Fang and M. Wang, Spectroscopic investigation on the binding of bioactive pyridazinone derivative to human serum albumin and molecular modeling, Colloids Surf. B Biointerfaces $\mathbf{6 5}$ (2008), 113-119. 


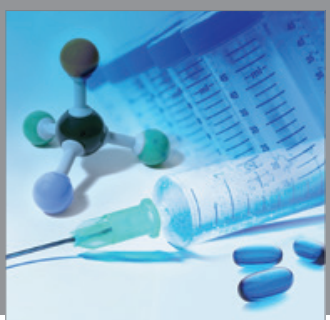

International Journal of

Medicinal Chemistry

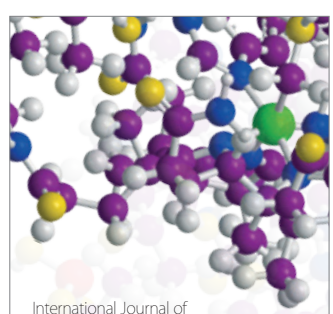

Carbohydrate Chemistry

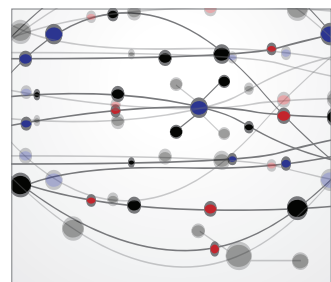

The Scientific World Journal
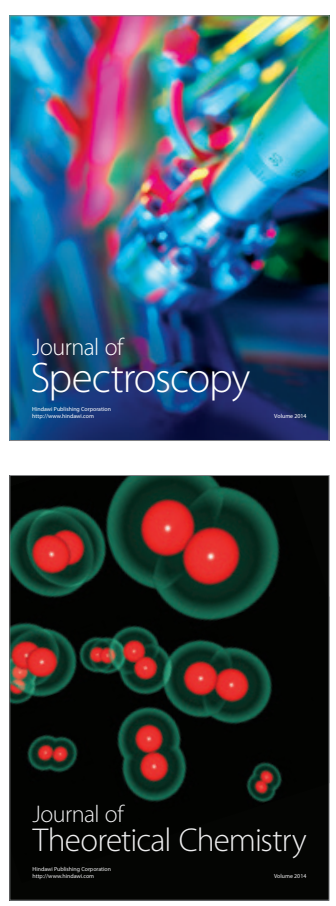
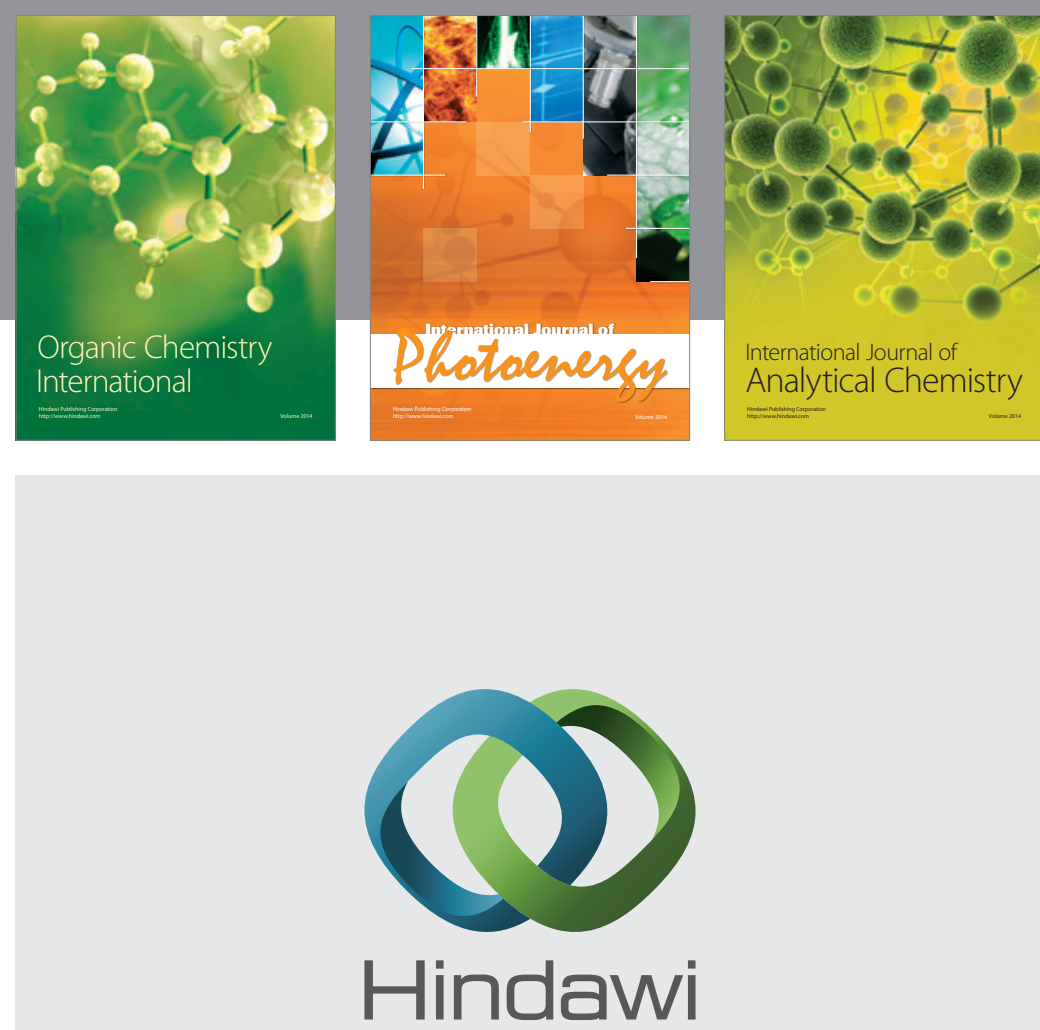

Submit your manuscripts at

http://www.hindawi.com
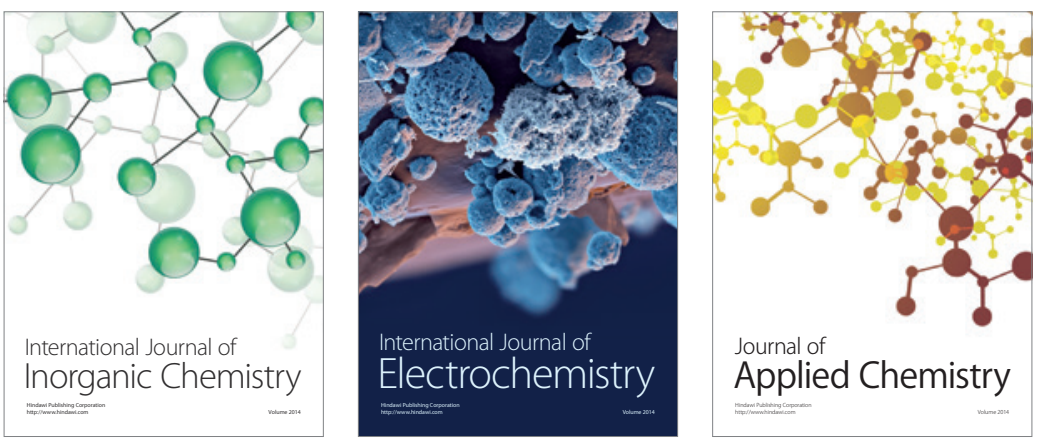

Journal of

Applied Chemistry
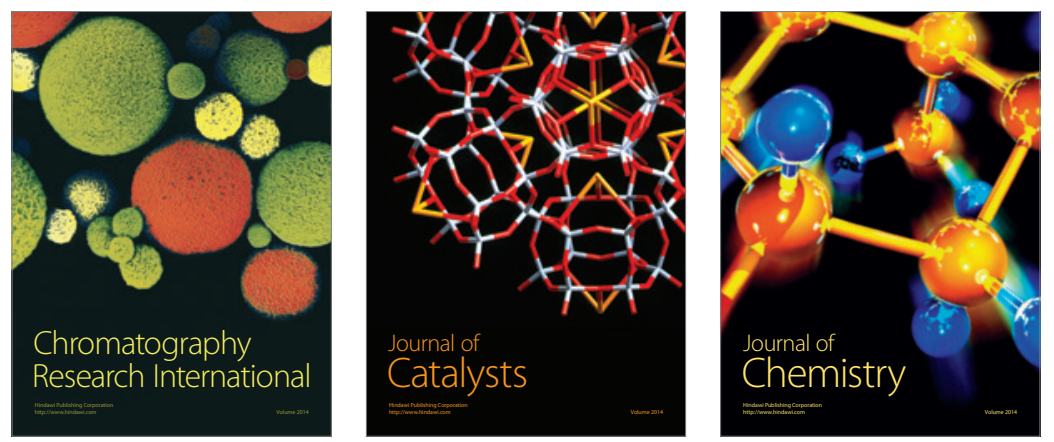
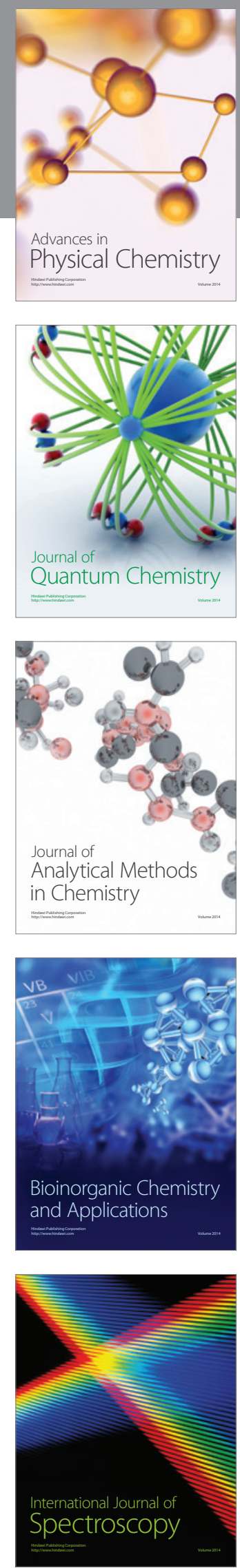